\title{
DETERMINATION OF PARTITION COEFFICIENTS AND AQUEOUS SOLUBILITIES BY REVERSE PHASE CHROMATOGRAPHY-II
}

\section{EVALUATION OF PARTITIONING AND SOLUBILITY MODELS}

\author{
YU-Ping Chin*, Walter J. Weber JR $\dagger$ and Thomas C. Voice $\ddagger$ \\ Water Resources and Environmental Engineering Program, 181 Engineering Building 1-A, \\ The University of Michigan, Ann Arbor, MI 48109, U.S.A.
}

\author{
(Received January 1986)
}

\begin{abstract}
Part I of this series examined the chemical and thermodynamic principles underlying the solubility and partitioning characteristics of non-electrolyte organic compounds in aqueous systems. It further considered those concepts which interrelate solubility and partitioning phenomena with retentive behavior in reverse phase liquid chromatography. Conceptual and predictive models which intercorrelate solubility, octanol/water partitioning, and reverse phase retention times were developed. Part II of the series evaluates the relative predictive abilities of these models for a wide range of different classes of organic pollutants. The results reveal that the reverse phase liquid chromatography models developed in Part I provide good estimates of octanol/water coefficients and aqueous solubilities from experimentally determined chromatographic retention times. Models structured to predict aqueous solubilities from octanol/water partition coefficient data were also found to provide reasonable estimates, but require as input physical and chemical parameters which are not readily accessible.
\end{abstract}

Key words -organic pollutants, octanol/water partition coefficient, activity coefficient, solubility, high performance reverse phase liquid chromatography

\section{INTRODUCTION}

Many organic contaminants commonly found in surface and subsurface waters are stable hydrophobic substances which readily partition into and concentrate within a variety of environmental compartments (biota, sediments, soils etc.). Models for quantifying and predicting such partitioning and bioaccumulation processes are frequently predicated on the aqueous solubilities $\left(S_{i}^{\omega}\right)$ and octanol/water partition coefficients $\left(K_{o w}\right)$ of the compounds in question. Direct experimental determinations of these two properties are tedious, however, and subject to significant experimental and analytical error. Empirical models based on "linear free energy" relationships can be used to estimate solubility and partitioning parameters, but such models do not take into account steric effects and specific molecular configurations which may affect the parameters. This paper, the second of a two part series, examines the feasibility of applying high performance reverse phase liquid chromatography (HPRPLC) for predict-

*Graduate Research Assistant in the Water Resources Program.

$†$ Professor of Environmental Engineering and Chairman of the University Water Resources Program.

$\ddagger$ Assistant Professor of Environmental Engineering: Michigan State University. ing the aqueous solubilities and octanol/water partition coefficients of hydrophobic organic pollutants.

Several investigators (McCall, 1975; Unger et al., 1978; Veith et al., 1979; McDuffie, 1980; Eadsforth and Moser, 1983; Rapaport and Eisenreich, 1984) have developed empirical correlations between octanol/water partition coefficients and HPRPLC retention times for hydrophobic organic compounds. These relationships are useful, but provide little insight to processes which may commonly control retentive behavior in reverse phase systems, solubility in water, and partitioning characteristics between water and immiscible organic phases. Yalkowski and Valvani (1980), Chiou et al. (1982), Amidon and Williams (1982) and Miller et al. (1985) have developed rigorous thermodynamic relationships between octanol/water partition coefficients and aqueous solubilities. This work has shown that the melting of a crystalline solid to form a "supercooled liquid" is an important step in the solubilization of solid organic substances, and that mutual saturation of water in octanol and octanol in water may play an important role in organic partitioning processes between two solvent systems.

The first paper in this two part series (Weber $e t$ al., 1986) examined the thermodynamic processes which govern the behavior of nonelectrolytic organic solutes in water and apolar organic solvents. A conceptual basis for relating the HPRPLC behavior of an or- 
ganic compound to its activity coefficient, solubility, and partitioning characteristics was provided. Several theoretical and semi-empirical models were developed for intercorrelating the aqueous solubilities, octanol/water partition coefficients, and retention behavior of nonelectrolytic organic solutes in reverse phase chromatography. Those models will be examined and their predictive capabilities compared in this second paper.

The first model to be evaluated utilizes high performance reverse phase liquid chromatography (HPRPLC) retention time data as a means for quantifying the partitioning characteristics of an organic nonelectrolyte in an octanol/water system. Octanol/water partition coefficients are estimated using a relatively simple relationship between $K_{o w}$ and the corrected retention time, $t_{c}$, of the solute

$$
\log K_{o w}=A \log t_{c}+C
$$

where $A$ and $C$ are experimentally calibrated constants, and $t_{c}$ is related to the reverse phase distribution coefficient $K_{R P}$ as developed in the previous paper [equation (44), Weber et al., 1986].

Three solubility models which alternatively utilize both octanol/water partition coefficients and HPRPLC retention times as "predictors" of the saturation-limit aqueous activity coefficient will also be compared. The models for predicting solubilities from octanol/water partitioning data are modified versions of the Yalkowski and Valvani (1980) model, and the Amidon and Williams solubility equation (1982). The first model assumes that non-electrolyte organic solutes behave ideally in the octanol phase, that the solubility of water in octanol is significant, and that the molar volume of the water-saturated octanol phase differs from that of the pure octanol phase. This yields the expression

$$
\log \left(S_{i}^{w}\right)=\left[\frac{-\Delta S_{f}\left(T_{m}-T\right)}{2.3 R T}\right]-\log K_{o w}+0.92
$$

where $S_{i}^{*}$ is the solubility of the target compound in water, $\Delta S_{j}$ is the entropy of fusion of the solute, and $T_{m}$ the melting point. The second $K_{o w}$-based model is similar to the first, but incorporates the Hildebrand-Scott regular solution theory (RST) to predict the nonideal behavior of an organic solute in a water-saturated octanol phase

$$
\log \left(S_{i}^{w}\right)=\frac{\left[-\Delta S_{f}\left(T_{m}-T\right)-\bar{V}_{i}\left(\delta_{i}-\delta_{o}^{\prime}\right)^{2}\right]}{2.3 R T-\log K_{o w}+0.92}
$$

where $\bar{V}_{i}$ is the molar volume of the solute, and $\delta_{i}$ and $\delta_{o}^{\prime}$ are the solute and water-saturated octanol solubility parameters, respectively.

A thermodynamic relationship between the aqueous activity coefficient at saturation and the HPRPLC retention behavior of a non-electrolyte organic compound was developed in the first paper of this series, and the following correlation between solubility and corrected retention time derived

$$
\log \left(S_{i}^{w}\right)=1.74-\frac{\Delta S_{f}\left(T_{m}-T\right)}{2.3 R T}
$$

$$
-\alpha \log \left(t_{i}\right)-\beta
$$

where $\alpha$ and $\beta$ are experimentally determined coefficients. Predictions of octanol/water partition coefficients and aqueous solubilities using the HPRPLC retention time models given in equations (1) and (4) respectively are compared in this paper to experimentally observed values. Additionally, HPRPLC predicted values of solubility are compared to the solubility estimates made from octanol/water partition coefficients using the models given in equations (2) and (3).

\section{MATERIALS AND METHODS}

The high performance liquid chromatograph used in this study consisted of a Waters M45 solvent delivery system and a Waters Lambda Max variable wavelength detector fitted with a Rheodyne 20- $\mu 1$ sample loop rotary injector, and a Whatman PXS-10/25 ODS-3 $C_{18}$ reverse phase column. The instrument was interfaced with a Houston Instruments strip chart recorder. Retention times were determined by setting the recorder to a prescribed chart speed and measuring the distance of the peaks from the point of injection. A stop watch was used periodically to verify the retention times. The mobile phase was comprised of HPLC-grade methanol (J. T. Baker) and distilled deionized water passed through a $0.45-\mu \mathrm{m}$ cut-off membrane filter (Millipore). Residual dissolved organic carbon in the water was generally less than $300 \mathrm{ppb}$. The mobile phase was degassed prior to the initiation of an experiment to eliminate any potential gas interference.

The compounds used in the study (with exception of the PCB isomers) were obtained from the Environmental Protection Agency (Research Triangle, North Carolina). Individual PCB isomers were obtained from Analabs/Foxboro Corporation. Most stock solutions were made up in HPLCgrade methanol, but those for the very hydrophobic substances were made up in HPLC-grade acetone. Stock solution concentrations ranged from 900 to $1100 \mathrm{mg} \mathrm{l}^{-1}$, and were diluted by a factor of 10 with methanol to working solution concentrations.

The HPRPLC instrument was calibrated with two mixtures comprised of five compounds each to determine the coefficients needed for the HPRPLC partition coefficient and aqueous solubility models [equations (I) and (4), respectively]. Standard I was comprised of phenol, chlorobenzene, napthalene, biphenyl, and anthracene. Standard II consisted of nitrobenzene, toluene, o-xylene, $o$ dichlorobenzene and 1,2,4-trichlorobenzene. Acetone was found to be relatively unretained by the $C_{18}$ column, and was chosen as an internal standard from which the retention times of all other compounds were referenced. The standards were run in duplicate on a daily basis to account for day to day instrumentation variations.

\section{RESULTS AND DISCUSSION}

\section{Octanol/water partition coefficient predictions}

Experimental octanol/water partition coefficients and corrected retention times, $t_{c}$ for the 10 aromatic standard compounds used to calibrate the HPRPLC instrument are listed in Table 1 . Corrected retention times are used in lieu of capacity factors to quantify reverse phase distribution coefficient for reasons de- 
Table 1. Octanol/water partition coefficient-log HPRPLC retention time calibration standards

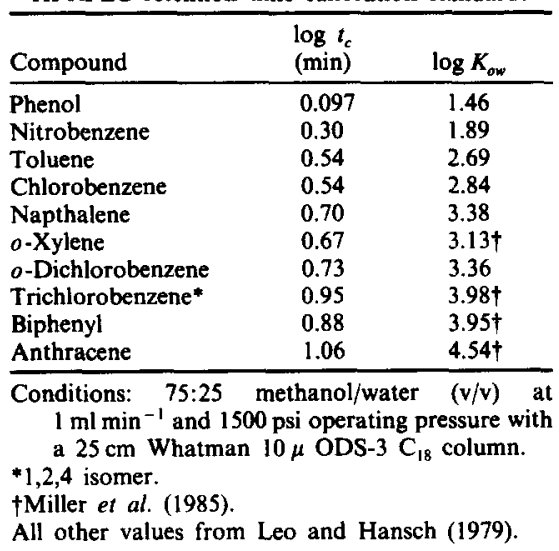

veloped in the Part I paper (Weber et al., 1986). Studies in our laboratory have shown that two commonly used "unretained" mobile phase tracers, sodium nitrate and acetone, both yield different mobile phase retention times. These findings agree with those of Krstulovic et al. (1982). The "corrected" retention time approach accounts for daily pertubations in the HPRPLC system since any chemical or physical change should equally affect both a target compound and an internal standard. Acetone was selected as the internal standard because it was found to be easily detected by u.v., relatively unretained by the stationary phase, and chemically innocuous to the HPLC instrumentation.

The $\log K_{o w}-\log t_{c}$ calibration curve of the solutes listed in Table 1 is plotted in Fig. 1. Least squares regression analysis of the data plotted in Fig. 1 yields

$$
\log \left(K_{\text {ow }}\right)=3.22 \log \left(t_{c}\right)+1.04
$$

$$
r=0.996 ; \quad n=10
$$

The "corrected" retention times for the standards represent the average of over 31 experimental runs. The Student's $t$-test results for the slope, $y$-intercept and correlation coefficient for a $95 \%$ confidence interval are $3.22( \pm 0.07), 1.04( \pm 0.04)$ and 0.996 $( \pm 0.01)$ respectively. The small deviations from the mean value at the $95 \%$ confidence level demonstrates that the reproducibility of the method is good, and agrees well with the findings of Eadsforth and Moser (1983). Continuous use of a column over time, however, will invariably bring about some deterioration, which can in turn alter the results. After 6 months of use, the Whatman column employed in this work exhibited some loss of resolution and separation efficiency.

The octanol/water partition coefficients of 18 organic priority pollutants calculated from equation (5) are presented in Table 2 , along with observed values of $K_{o w}$ for these compounds. The absolute deviation between the $t_{c}$-based calculations and the observed values ranges from 0.07 to $0.80 \mathrm{log}$ units with an

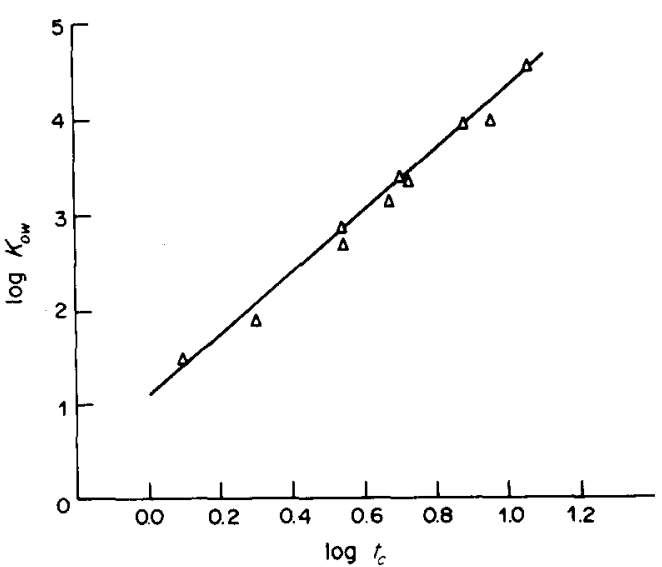

Fig. 1. Correlation between the octanol/water partition coefficients and corrected retention times for the calibration standards.

average of 0.31 . Using this method octanol/water partition coefficients can be estimated to within $6.71 \pm 3.96 \%$ of the experimental $\log$ values reported in the literature. Our findings agree well with those of Veith et al. (1979). McDuffie (1980), Eadsforth and Moser (1983) and Rapaport and Eisenreich (1984). Regression analysis between the observed and predicted $\log \left(K_{\text {ow }}\right)$ values yields the correlation

$$
\begin{array}{r}
\log \left(K_{o w_{\text {obe }}}\right)=0.92 \log \left(K_{\text {ow pred. }_{\text {pro }}}\right)+0.33 ; \\
r=0.960 ; n=18
\end{array}
$$

which is plotted in Fig. 2. Linearity exists between the two pooled sets of values over a span of four orders of magnitude. However, deviations from linearity appear at very high $\log$ octanol/water partition coefficient values $\left(\log K_{o w}>6\right)$. This is probably caused by the "mutual saturation effect". Chiou et al.

\begin{tabular}{|c|c|c|c|}
\hline Compound & $\log \left(t_{c}\right)$ & $\log K_{o w(p r o d)}$ & $\log K_{\text {ow (obs) }}$ \\
\hline Benzene & 0.40 & 2.33 & $2.13^{*}$ \\
\hline Acenapthene & 1.02 & 4.33 & $3.92 \dagger$ \\
\hline Acenapthylene & 0.78 & 3.55 & $4.07 \S$ \\
\hline Phenanthrene & 1.04 & 4.39 & $4.46 \ddagger$ \\
\hline Fluoranthene & 1.18 & 4.84 & $5.22+$ \\
\hline Fluorene & 0.95 & 4.10 & $4.18+$ \\
\hline Pyrene & 1.22 & 4.97 & $5.18 \dagger$ \\
\hline $2,2^{\prime}, 4,5-\mathrm{PCB}$ & 1.41 & 5.58 & $5.73+$ \\
\hline $2,3,4,5,6-\mathrm{PCB}$ & 1.82 & 6.90 & $6.30 \dagger$ \\
\hline Pentachlorobenzene & 1.46 & 5.74 & $5.19 \ddagger$ \\
\hline Hexachlorobenzene & 1.70 & 6.51 & $6.18 \S$ \\
\hline$p, p^{\prime}-\mathrm{DDE}$ & 1.63 & 6.29 & $5.69 \ddagger$ \\
\hline$p, p^{\prime}-\mathrm{DDD}$ & 1.29 & 5.19 & 5.998 \\
\hline$p, p^{\prime}-\mathrm{DDT}$ & 1.56 & 6.06 & $5.98 \S$ \\
\hline o-Chlorophenol & 0.40 & 2.32 & $2.17^{*}$ \\
\hline 2,4-Dichlorophenol & 0.57 & 2.87 & $2.75 \S$ \\
\hline 2,4,6-Trichlorophenol & 0.70 & 3.29 & $3.38^{*}$ \\
\hline Pentachlorophenol & 1.14 & 4.71 & 5.017 \\
\hline
\end{tabular}

Table 2. A comparison of octanol/water partition coefficients predicted from equation (3) and HPRPLC retention data with experimentally measured literature values

*Leo and Hansch (1979).

†Miller et al. (1985).

$\ddagger$ Mackay (1982).

\$Callahan et al. (1979). 


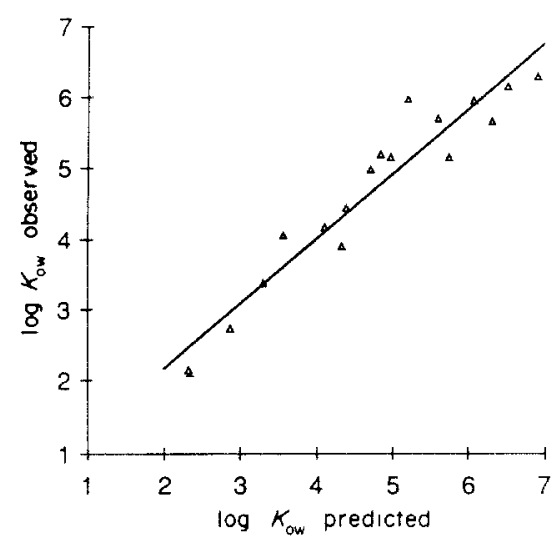

Fig. 2. Correlation between HPRPLC-predicted octanol water partition coefficients and experimentally measured values.

(1982) observed that this effect is most pronounced with compounds of very low solubility. The HPRPLC model is calibrated using a group of moderately hydrophobic compounds which are not as strongly affected by "mutual saturation". The resultant regression line is extrapolated into the high octanol/water partition coefficient region, and the model will tend to slightly over-predict $\log K_{o w}$ values for very hydrophobic compounds. Nonetheless, the coefficients of determination indicate that the agreement between the two data sets is good in that the slope of the line is close to unity and the $y$-intercept approaches the origin.

This technique can also be used to estimate the octanol/water partition coefficients of weakly acidic aromatic compounds (most notably phenols). The $\mathrm{p} K_{a}$ 's for many of these compounds are lower than the $\mathrm{pH}$ of the mobile phase. In these cases, the target species remain ionized and pass through the reverse phase column very quickly. Veith et al. (1979) reported that 2,4,5-trichlorophenol, $m$-chlorobenzoic acid, and diphenylamine eluted very rapidly and yielded substantially lower estimates of octanol/water partition coefficients than were actually observed, even when the $\mathrm{pH}$ of the mobile phase was lowered to 4.0. We have observed a similar effect with 2,4,6-trichlorophenol and pentachlorophenol, which have $\mathrm{p} K_{a}$ 's of 5.99 and 4.74 , respectively (Ugland $e t$ al., 1981), when using an unbuffered methanol/water mobile phase $(\mathrm{pH}=7.5)$. However, acidification of the mobile phase with phosphoric acid to a $\mathrm{pH}$ of 3.0 was found to keep the solutes in an unionized state, and the resultant retention times were observed to be much more accurate predictors of octanol/water partition coefficients for these compounds than were those attained at the higher $\mathrm{pH}$ value.

HPRPLC estimated octanol/water partition coefficients thus seem to agree well with measured values reported in the literature. The HPRPLC technique is less time consuming and less subject to error than the conventional shake-flask method used for direct experimental measurement of $K_{o w}$ values. Further, "corrected" retention times may be used to directly estimate sediment/soil partition coefficients. Rapaport and Eisenreich (1984) have observed that the $C_{1 \times}$ stationary phase properties are similiar to those of soil and sediment particles coated with natural organic matter. They hypothesized that the sorption of an organic nonelectrolyte onto $\mathrm{C}_{18}$ may more accurately represent sorptive processes in natural aquatic systems than the partitioning of an organic solute between water and octanol. This hypothesis deserves further examination.

\section{Solubility model predictions}

The predictive capabilities of the three solubility models are compared in this section. Aqueous solubilities estimated by the modified Yalkowski and Valvani model [equation (2)] are compared in Table 3 to experimental solubilities measured by other investigators (Yalkowski and Valvani, 1980; Callahan (ed.), 1979; Miller et al., 1985). The compounds examined in this phase of the study were restricted to hydrophobic nonelectrolytes, and excluded substances which may ionize and/or undergo specific molecular interactions with the aqueous phase (i.e. organic acids and phenolic compounds). A detailed derivation of the model is presented in the first paper of this series (Weber et al., 1986). Inspection of the solubility information presented in Table 3 reveals that the modified Yalkowski-Valvani model predictions come within an order of magnitude of the observed values for many of the solutes listed. However large differences between predicted and observed or measured solubilities may be noted for the PCBs, DDT and DDE. The average absolute deviation between estimated and observed values is $0.81 \mathrm{log}$ units, with a maximum deviation of 1.91. Regression analysis between the observed and predicted aqueous solubilities presented in Table 3 yields

$$
\begin{aligned}
\log \left(S_{i_{\text {obs. }}}^{n}\right)=0.86 \log \left(S_{i_{\text {pred }}}^{n}\right)+1.53 ; \\
r=0.81 ; n=23 .
\end{aligned}
$$

It is apparent that a correlation exists, but the coefficients of the correlation indicate that the model does not provide generally satisfactory estimates of aqueous solubilities.

The limited predictive capability of the model given by equation (2) can be referenced to the physicochemical behavior of non-electrolyte organic solutes in octanol/water systems. All the target compounds are nonpolar in nature, and may be expected to behave solvophobically in water. This is attested by their very low solubilities and large octanol/water partition coefficients. While it is apparent from the data that solvophobic interactions are important in the development of correlations between partitioning and solubility, other factors are also evidently involved 
Table 3. A comparison of aqueous solubilities predicted from equation (2) with experimentally determined literature values

\begin{tabular}{|c|c|c|c|c|}
\hline Compound & $T_{m}\left({ }^{\circ} \mathrm{C}\right)$ & $\log K_{o w}$ & $\log S_{\text {(pred) }}^{w}$ & $\log S_{l_{(0 b 0)}}^{w}$ \\
\hline Napthalene & 80 & 3.38 & -2.97 & $-3.61^{*}$ \\
\hline Anthracene & 216 & 4.54 & -5.51 & $-6.38^{*}$ \\
\hline Fluorene & 116 & 4.18 & -4.18 & $-4.92^{*}$ \\
\hline Phenanthrene & 101 & 4.46 & -4.20 & $-5.15^{*}$ \\
\hline Acenapthene & 96 & 3.92 & -3.70 & $-4.59^{*}$ \\
\hline Fluoranthene & 111 & 5.22 & -5.15 & $-5.90^{*}$ \\
\hline Pyrene & 156 & 5.18 & -5.56 & $-6.18^{*}$ \\
\hline Benzene & 0 & 2.13 & -1.21 & $-1.62^{*}$ \\
\hline Chlorobenzene & -250 & 2.84 & -1.92 & $-2.35^{*}$ \\
\hline Dichlorobenzene§ & -25 & 3.36 & -2.44 & $-3.20^{*}$ \\
\hline Trichlorobenzene & 17 & 3.98 & -3.06 & $-3.72^{*}$ \\
\hline Pentachlorobenzene & 85 & 5.19 & -4.86 & $-5.65^{*}$ \\
\hline Hexachlorobenzene & 228.5 & 6.18 & -7.29 & $-7.76^{*}$ \\
\hline Biphenyl & 71 & 3.95 & -3.53 & $-4.34^{*}$ \\
\hline 2-PCB & 32.3 & 4.50 & -3.58 & $-4.57 \dagger$ \\
\hline $2,3,4,5,6-\mathrm{PCB}$ & 74.6 & 6.30 & -5.87 & $-7.77^{+}$ \\
\hline$p, p^{\prime}-\mathrm{DDE}$ & 89 & 5.69 & -5.41 & $-7.32 \ddagger$ \\
\hline$p, p^{\prime}-\mathrm{DDT}$ & 108 & 5.98 & -5.88 & $-7.13 \ddagger$ \\
\hline$p, p^{\prime}-\mathrm{DDD}$ & 112 & 5.99 & -5.93 & $-6.55 t$ \\
\hline Toluene & -95 & 2.69 & -1.77 & $-2.20 \dagger$ \\
\hline$o-\mathrm{X}$ ylene & -25 & 3.13 & -2.21 & $-2.75 \dagger$ \\
\hline Trimethylbenzene** & -25 & $3.55+$ & -2.63 & $-3.26 \dagger$ \\
\hline Ethylbenzene & -95 & $3.13 \dagger$ & -2.21 & $-2.68 \dagger$ \\
\hline
\end{tabular}

*Values from Yalkowski and Valvani (1980).

†Values from Miller et al. (1985)

†Values from Callahan (1979).

SOrtho isomer.

$1,2,3$ isomer.

$* * 1,2,4$ isomer. Solubilities are in units of $\mathrm{mol} \mathrm{l}^{-1}$

Chiou et al. (1982) have claimed that the saturation of octanol in the water phase may play a significant role in altering the solubility of a nonelectrolyte. They observed that the aqueous solubilities of DDT and hexachlorobenzene are enhanced by factors of 160 and $80 \%$ respectively if octanol is present. The magnitude of this phenomenon is impossible to predict a priori with existing thermodynamic models, however, and must be measured directly. Miller et al. (1985) have recently investigated the effect of mutual saturation and found that the presence of octanol in the aqueous phase plays an insignificant role. They concluded that enhanced solubilization can occur only if the octanol interacts specifically with the solute molecules, and even this would affect solubility only on the order of a few percent. If the presence of dissolved octanol in water does in fact not affect the aqueous solubility of nonelectrolytic organic substances, then deviations between observed solubilities and those predicted by equation (2) must be due at least in some measure to nonideal behavior on the part of the target substance in the organic phase. Miller et al. (1985) experimentally measured the solubilities of organic solutes in water saturated octanol, and concluded that there exists no a priori method for estimating activity coefficients in such systems. Amidon and Williams (1982), however, applied the regular solution theory in their solubility model to estimate the solute activity coefficient in the octanol phase. The model given in equation (3) also assumes that organic solutes behave as regular solutions in water-saturated octanol. The solubility parameter, $\delta s^{\prime}$, of a mixed solvent can be estimated using the equation

$$
\delta s^{\prime}=\Sigma \phi \delta s
$$

where $\phi$ and $\delta s$ are the volume fraction and solubility parameters for each solvent (Hildebrand et al., 1970; Karger et al., 1973). A solubility parameter value of 21 for water (Karger et al., 1973) and 10.3 for octanol (Amidon and Williams, 1982) yields a solubility parameter of 10.8 for a water-saturated octanol phase.

The limitations of the regular solution theory (RST) were examined in the first part of this series (Weber et al., 1986). The RST model can adequately predict activity coefficients for organic solutes in apolar solvents provided that physical dispersion forces dominate all molecular interactions and that specific molecular interactions such as hydrogen bonding are absent (Hildebrand et al., 1970; Barton, 1975; Hagen and Flynn, 1983; Campbell et al., 1983). The presence of water would alter the molar volume of the octanol phase and effect hydrogen bonding with alcoholic functional groups, but solute/solvent interactions seem to be restricted to physical dispersion forces between the nonelectrolytic solute molecule and the aliphatic octanol chain. The assumption that hydrophilic/hydrophobic interactions are segregated in some manner justifies the application of the RST model for estimating the infinite dilution solute activity coefficient in the water-saturated octanol phase. This assumption is reasonably valid for solutes having molar volumes lower than that of octanol. If the solute's molar volume exceeds that of the octanol phase $\left(157.7 \mathrm{~cm}^{3} \mathrm{~mol}^{-1}\right)$, however, hydrophobic and hydrophilic interactions may become less segregated (Miller et al., 1985), and the behavior of the solute may deviate from regular solution behavior. Miller et al. (1985) have observed that the "pseudo-solubility" of solutes in octanol saturated with water decreases with increasing molar volume.

Predictions of aqueous solubilities using the model given in equation (3) are presented in Table 4. Some of the compounds listed in Table 3 were excluded from this analysis because there was insufficient physicochemical data in the literature from which to determine their solubility parameters. Comparison of the predictions in Table 4 with corresponding values presented in Table 3 indicates that inclusion of the water-saturated octanol solute activity coefficient in equation (3) greatly improves the model's predictive capabilities for the solutes listed. The average absolute deviation between observed and predicted solubilities given in Table 4 is $0.35 \log$ units with a maximum deviation of 0.75 . The model can predict $\log$ aqueous solubilities to within $9.09 \pm 5.5 \%$ of the values found in the literature. The regression analysis between observed and aqueous solubilities represented in equation (9)

$$
\begin{aligned}
\log \left(S_{i_{\text {obs. }}}^{w}\right)=1.01(\log )\left(S_{i_{\text {pred. }}}^{\omega}\right) & -0.30 ; \\
r & =0.987 ; n=17
\end{aligned}
$$


Table 4. A comparison of aqueous solubilities predicted from equation (3) with observed values

\begin{tabular}{|c|c|c|c|c|c|}
\hline Compound & $\bar{V}$ & $\delta$ & $\log K_{o w}$ & $\log S_{i \text { (pred })}^{w}$ & $\log S_{i_{\text {obb }}^{*}}^{N^{\prime}}$ \\
\hline Napthalene & 148 & 9.7 & 3.38 & -3.11 & -3.61 \\
\hline Anthracene & 197 & 9.9 & 4.54 & -5.71 & -6.38 \\
\hline Fluorene & 188 & 9.7 & 4.18 & -4.32 & -4.92 \\
\hline Phenanthrene & 199 & 9.8 & 4.46 & -4.43 & -5.15 \\
\hline Acenapthene & 173 & 9.1 & 4.33 & -4.47 & -4.59 \\
\hline Benzene & 89 & 9.2 & 2.13 & -1.38 & -1.62 \\
\hline Chlorobenzene & 117 & 9.5 & 2.84 & -2.06 & -2.35 \\
\hline Dichlorobenzene & 138 & 9.5 & 3.36 & -2.61 & -3.20 \\
\hline Trichlorobenzene & 159 & 9.3 & 4.26 & -3.60 & -3.72 \\
\hline Pentachlorobenzene & 200.5 & 10.3 & 5.19 & -4.90 & -5.65 \\
\hline Hexachlorobenzene & 221 & 9.0 & 6.18 & -7.80 & $\ldots 7.76$ \\
\hline Bipheny! & 185 & 8.3 & 3.95 & -4.33 & -4.34 \\
\hline 2-Chlorobiphenyl & 164 & 9.0 & 4.50 & -4.00 & -4.57 \\
\hline Toluene & 106 & 8.9 & 2.69 & -2.05 & --2.20 \\
\hline$o$-Xylene & 121 & 9.0 & 3.13 & -2.50 & -2.75 \\
\hline Ethylbenzene & 123 & 8.8 & 3.13 & -2.57 & -2.68 \\
\hline 1,2,3-Methylbenzene & 134 & 8.7 & 3.55 & -3.06 & -3.26 \\
\hline
\end{tabular}

Solute solubility parameters were computed from heat of vaporization data found in Weast (1980).

Molar volumes were calculated from solute molecular weight and density data found in Weast (1980).

also clearly indicates an improvement in the predictive capabilities of equation (3) over those of equation (2). In addition the model does not seem to be affected by solutes with molar volumes greater than that of octanol, and this seems to suggest that nonpolar interactions still predominate between these solutes and the solvent. It thus appears that incorporation of the regular solution theory to account for deviations from ideal solution behavior in watersaturated octanol significantly enhances the predictive capabilities of models which utilize octanol/water partition coefficients for estimation of a solute's aqueous solubility.

The availability of solubility parameter data for hydrophobic organic contaminants is limited. The model given in equation (4) obviates the need for such data by utilizing HPRPLC retention time, which can be readily determined experimentally, as an indirect measure of the saturation-limit aqueous activity coefficient. The activity coefficients and "corrected" retention times of the nine standards used in this work for calibration purposes are listed in Table 5. Phenol was not used as a standard for the reasons stated previously. Activity coefficients for the target

Table 5. Activity coefficient and HPRPLC retention time calibration data

\begin{tabular}{lcc}
\hline Compound & $\begin{array}{c}\log \text { activity } \\
\text { coeff. }\end{array}$ & $\log t_{c}$ \\
\hline Nitrobenzene & 3.49 & 0.30 \\
Toluene & 3.97 & 0.54 \\
Chlorobenzene & 4.09 & 0.54 \\
Napthalene & 4.82 & 0.70 \\
o-Xylene & 4.56 & 0.67 \\
o-Dichlorobenzene & 4.79 & 0.73 \\
l,2,4-Trichlorobenzene & 5.49 & 0.95 \\
Biphenyl & 5.72 & 0.88 \\
Anthracene & 6.25 & 1.06 \\
\hline
\end{tabular}

All activity coefficients are calculated using the equations in Tsounopolous and Prausnitz (1971) and verified with measured aqueous solubility data.

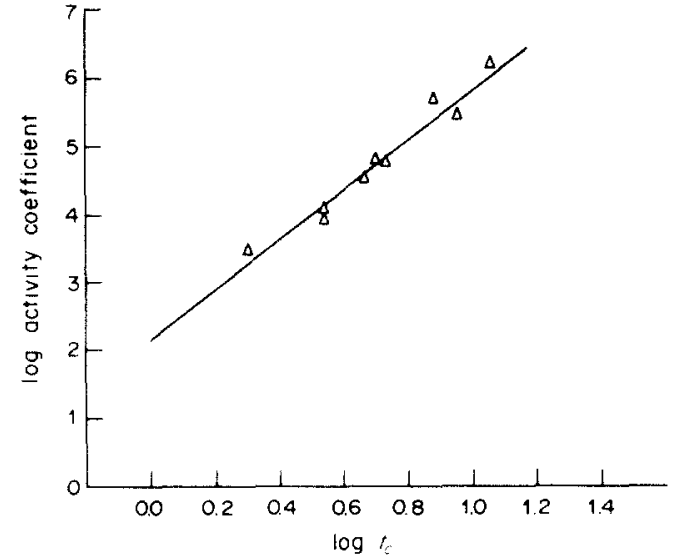

Fig. 3. Correlation between the corrected retention times and saturation level aqueous activity coefficients for the calibration standards.

compounds were approximated according to the methods used by Tsonopoulos and Prausnitz (1971). Agreement between the aqueous solubilities determined by the estimated activity coefficients and those reported in the literature are excellent. Model calibration was done by correlating measured $t_{c}$ values with calculated values for the $\log$ activity coefficient. The calibration data and correlation curve are plotted in Fig. 3. Regression of the data yields the following equation for the correlation curve

$$
\begin{aligned}
\log \left(\gamma_{i}^{w}\right)=3.75 \log \left(t_{c}\right)+2.14 ; & \\
r & =0.988 ; \quad n=9 .
\end{aligned}
$$

Introduction of the two empirical coefficients from equation (10) into equation (4) yields

$$
\begin{aligned}
\log \left(S_{i}^{*}\right)=1.74-\frac{\Delta S_{f}\left(T_{m}-T\right)}{2.3 R T} & \\
& -3.75 \log \left(t_{c}\right)-2.14 .
\end{aligned}
$$

Aqueous solubilities estimated from equation (11) are listed in Table 6, along with observed values taken from the literature, and relationships between predicted and observed values are depicted graphically in Fig. 4. The average absolute deviation of observed values from the predicted values is $0.27 \log$ units with a maximum deviation of 1.01 units. Stated in terms of predictive capability, the results indicate that the model can predict log aqueous solubilities to within $6.14 \pm 5.7 \%$ of the observed values reported in the literature. Regression analysis between estimated and experimentally measured solubilities yields the correlation

$$
\begin{array}{r}
\log \left(S_{i_{\text {obs }}}^{w}\right)=0.980 \log \left(S_{i_{\text {pred }}}^{w}\right)-0.03 ; \\
r=0.981 ; \quad n=22 .
\end{array}
$$

Equation (12) indicates clearly that aqueous solubilities can be predicted with reasonable accuracy using equation (4) and HPRPLC determined 
Table 6. A comparison of aqueous solubilities predicted from equation (11) and HPRPLC data with experimentally measured literature values

\begin{tabular}{|c|c|c|c|}
\hline Compound & $\log t_{c}$ & $\log S_{i(\text { prod })}^{w}$ & $\log S_{4 \text { (obs) }}^{w}$ \\
\hline Benzene & 0.40 & -1.90 & -1.62 \\
\hline Napthalene & 0.70 & -3.56 & -3.61 \\
\hline Acenapthene & 1.02 & -4.92 & -4.59 \\
\hline Acenapthylene* & 0.78 & -3.99 & -4.59 \\
\hline Fluorene & 0.95 & -4.86 & -4.92 \\
\hline Fluoranthene & 1.18 & -5.67 & -5.90 \\
\hline Phenanthrene & 1.04 & -5.05 & -5.15 \\
\hline Pyrene & 1.22 & -6.27 & -6.18 \\
\hline Dichlorobenzene & 0.73 & -3.14 & -3.20 \\
\hline Trichlorobenzene & 0.95 & -3.96 & -3.72 \\
\hline Pentachlorobenzene & 1.46 & -6.45 & -5.65 \\
\hline Hexachlorobenzene & 1.70 & -8.77 & -7.76 \\
\hline Biphenyl & 0.88 & -4.16 & -4.34 \\
\hline $2,3,4,5,6-\mathrm{PCB}$ & 1.82 & -7.71 & -7.77 \\
\hline$p, p^{\prime}-\mathrm{DDE}$ & 1.63 & -7.13 & -7.32 \\
\hline$p, p^{\prime}$-DDT & 1.56 & -7.07 & -7.13 \\
\hline$p, p^{\prime}-\mathrm{DDD}$ & 1.29 & -6.10 & -6.55 \\
\hline Chlorobenzene & 0.54 & -2.42 & -2.35 \\
\hline Toluene & 0.54 & -2.42 & -2.20 \\
\hline$o$-Xylene & 0.67 & -2.91 & -2.75 \\
\hline Ethylbenzene & 0.74 & -3.18 & -2.68 \\
\hline Anthracene & 1.06 & -6.27 & -6.38 \\
\hline
\end{tabular}

*Callahan et al. (1979).

All other references for the observed aqueous solubility values are given in Table 3

coefficients. Large deviations between observed and predicted log aqueous solubilities may be due in part to violation of the assumption that differences between the solid and liquid phase solute heat capacities are negligible (Weber et al., 1986). It is plausible that the model's predictive capability may be enhanced by accounting for these differences; however, heat capacity data is not readily found in the literature for many compounds.

Judging from the agreement between predicted and observed solubilities of target solutes the HPRPLC technique would seem directly applicable as a means for quickly screening the properties of organic pollutants, particularly those compounds for which only limited physicochemical data is otherwise available. Most organic compounds are analyzable by reverse phase chromatography with the proper detector. The model given in equation (4) circumvents many of the problems which limit the usefulness of octanol/water-aqueous solubility models (i.e. limited availability of octanol/water partition coefficient and solubility parameter data, and the effects of mutual saturation). Further, it provides conceptual insight into the processes which govern the physicochemical behavior of organic substances in aquatic systems.

\section{CONCLUSIONS}

It is apparent from the foregoing analysis that high performance reverse phase liquid chromatography holds promise as a method for predicting and understanding the physicochemical behavior of organic priority pollutants. This technique, when coupled with appropriate models, enables prediction of both octanol/water partition coefficients and aqueous

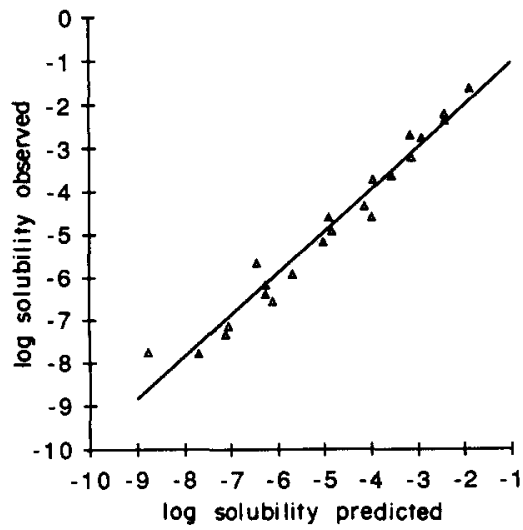

Fig. 4. Correlation between HPRPLC-predicted aqueous solubilities and experimentally measured values.

solubilities with speed, precision and reasonable accuracy. The technique is potentially useful as a means for quickly and accurately predicting bioconcentration and sediment/soil sorption coefficients. Moreover, unlike most alternative methods for the prediction of environmental fate, the technique is not constrained by the lack of requisite physicochemical data for the compounds of interest.

Acknowledgements - The authors thank Carol Leedom and Carole Peven for their help in the laboratory and data analysis. The work presented in this series was supported in part by the Michigan Sea Grant Program and the Cooperative Program between the Great Lakes Environmental Research Laboratory of the National Oceanic and Atmospheric Administration and the University of Michigan.

\section{REFERENCES}

Amidon G. L. and Williams N. A. (1982) A solubility equation for nonelectrolytes. Int. J. Pharm. 11, 249-256.

Arbuckle W. B. (1983) Estimating activity coefficients for use in calculating environmental parameters. Envir. Sci. Technol. 17, 537-542.

Barton A. F. M. (1975) Solubility parameters. Chem. Rev. 75, 731-751.

Callahan (ed.) (1979) Water Related Environmental Fate of 129 Priority Pollutants. EPA440/4-79-029a/029b.

Campbell J. R., Luthy R. G. and Carrondo M. J. T. (1983) Measurement and prediction of distribution coefficients for wastewater aromatic solutes. Envir. Sci. Technol. 17, $582-590$.

Chiou C. T., Schmedding D. W. and Manes M. (1982) Partitioning of organic compounds in octanol-water systems. Envir. Sci. Technol. 16, 4-10.

Eadsforth C. V. and Moser P. (1983) Assessment of reverse phase chromatographic methods for determining partition coefficients. Chemosphere 12, 1459-1475.

Hagen T. A. and Flynn G. A. (1983) Solubility of hydrocortisone in organic and aqueous media: evidence for regular solution behavior in apolar solvents. J. Pharm. Sci. 72, 409-413.

Hildebrand J. H., Prausnitz J. M. and Scott R. L. (1970) Regular and Related Solutions. Van Nostrand Reinhold, New York. 
Karger B. L., Snyder L. R. and Horvath C. (1973) An Introduction to Separation Science. Wiley, New York.

Krstulovic A. M., Colin H. and Guichon G. (1982) Comparison methods used for the determination of void volume in reverse-phase liquid chromatography. Analyt. Chem. 54, 2438-2443.

Leo A. and Hansch C. (1979) Substituent Constant for Correlation Analysis in Chemistry and Biology. Wiley, New York.

Locke D. C. (1974) Selectivity in reverse-phase liquid chromatography using chemically bonded stationary phases. J. Chromat. Sci. 12, 433-437.

McCall J. M. (1975) Liquid-liquid partition coefficients by high performance liquid chromatography. J. med. Chem. $18,549-552$.

MacKay D. (1982) Correlation of bioconcentration factors. Envir. Sci. Technol. 16, 274-278.

McDuffie B. (1980) Estimation of octanol/water partition coefficients for organic pollutants using reverse phase high performance liquid chromatography. Chemosphere 10, $73-83$

Miller M. M., Wasik S. P., Huang G., Shiu W. and MacKay D. (1985) Relationships between octanol-water partition coefficient and aqueous solubility. Envir. Sci. Technol. 19, 522-529.

Rapaport R. A. and Eisenreich S. (1984) Chromatographic determinations of octanol-water partition coefficients for
58 polychlorinated biphenyl cogeners. Envir. Sci. Technol. 18, $163-168$.

Tsonopoulos C. and Prausnitz J. M. (1971) Activity coefficients of aromatic solutes in dilute aqueous solutions. Ind. Engng Chem. Fund. 10, 593-599.

Ugland K., Lundanes E., Griebrokk T. and Bjorseth A. (1981) Determination of chlorinated phenols by high performance liquid chromatography. J. Chromat. 213, 83-90.

Unger S. H., Cook J. R. and Hollenberg J. S. (1978) Simple procedure for determining octanol-aqueous partition coefficients, distribution and ionization coefficients with reverse phase high performance liquid chromatography. J. Pharm. Sci. 67, 1364-1367.

Veith G. D., Austin N. M. and Morris R. T. (1979) A rapid method for estimating $\log P$ for organic chemicals. Wat. Res. 13, 43- 47.

Weast R. C. (1980) Handbook of Chemistry and Physics. Chemical Rubber Co.

Weber W. J. Jr, Chin Y. P. and Rice C. P. (1986) Determination of partition coefficients and aqueous solubilities by reverse phase chromatography-I. Theory and background. Wat. Res. 20, 1433-1442.

Yalkowski S. H. and Valvani S. C. (1980) Solubility and partitioning-I. Solubility of nonelectrolytes in water. J. Pharm. Sci. 69, 912-922. 